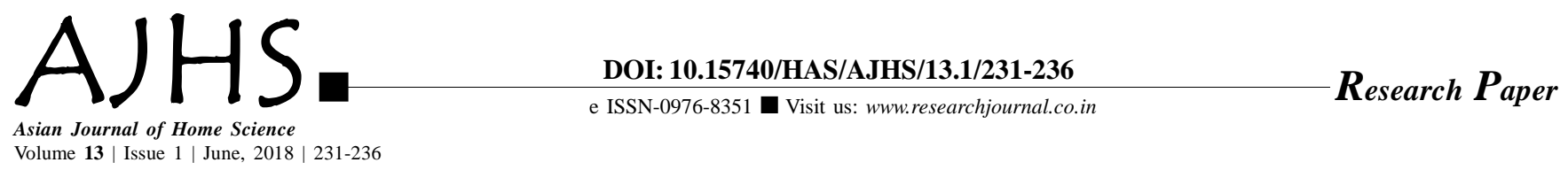

\title{
Ergonomic study of visual discomforts due to lighting conditions in rural and urban homes of Ludhiana district
}

Shinam Bhalla, Narinderjit Kaur and Sharanbir Kaur Bal

Received: 09.11.2017; Revised: 07.04.2018; Accepted: 26.04.2018

See end of the paper for authors' affiliations

\section{Sharanbir Kaur Ba}

Department of Family Resource

Management, College of Home

Science, Punjab Agricultural

University, Ludhiana (Punjab)

India

Email : balsharanbir@pau.edu
ABSTRACT : The present study entitled ergonomic study of visual discomforts due to lighting conditions in rural and urban homes of Ludhiana district was undertaken to study the visual discomforts faced by the respondents in rural and urban homes of Ludhiana district, to assess the impact of inadequate lighting conditions on human health. Study was conducted as household survey in rural and urban homes in Ludhiana district. Results of the study revealed that from both urban and rural area various visual discomforts like declined vision, eye strain, glare in eyes, were observed due to inadequate light. Some subjective scales used also highlighted that respondents felt visual discomforts due to poor lighting. Ocular Surface Disease Index (OSDI) scale was used to analyze symptoms related to visual problems and it was found that in rural area maximum number $(88.33 \%)$ of the respondents and in urban area around half $(53.33 \%)$ of the respondents were having mild level of dry eyes disease followed by moderate one fourth $(25.00 \%)$ in urban area and 11.67 per cent in rural area. Only 16.67 per cent of the respondents in urban area were having high level of dry eye diseases. Whereas, Aramuc Scientific Scale showed that in urban area one third (33.33\%) of the respondents and in rural area 20.00 per cent of the respondents were having true dry eyes. Therefore, lighting of the house should be ergonomically designed which can help to reduce the visual problems. These corrective measures can be achieved by proper lighting, right positioning of light fixtures, proper type of light source should be used.

KEY WORDS: Indadequate lighting, Ergonomics, Visual discomforts, Glare, Ocular surface disease Index (OSDI), Aramuc scientific scale

- HOW TO CITE THIS PAPER : Bhalla, Shinam, Kaur, Narinderjit and Bal, Sharanbir Kaur (2018). Ergonomic study of visual discomforts due to lighting conditions in rural and urban homes of Ludhiana district. Asian J. Home Sci., 13 (1) : 231-236, DOI: 10.15740/HAS/AJHS/13.1/231-236. Copyright@ 2018: Hind Agri-Horticultural Society. 